Textures and Microstructures, Vol. 31, pp. 231-238 Reprints available directly from the publisher Photocopying permitted by license only
(C) 1999 OPA (Overseas Publishers Association) N.V.

Published by license under the Gordon and Breach Science Publishers imprint. Printed in Malaysia.

\title{
THE INFLUENCE OF MOLYBDENUM ON THE TEXTURE AND MAGNETIC ANISOTROPY OF Fe- $x$ Mo-5Ni-0.05C ALLOYS
}

\author{
H. ABREU ${ }^{a}$, J.R. TEODÓSIO ${ }^{a}$, J. NETO $^{a}$, M. SILVA $^{a}$ \\ and C.S. DA COSTA VIANA ${ }^{b, *}$ \\ a Department of Metallurgical and Materials Engineering, \\ Federal University of Rio de Janeiro, 21945-970, Rio de Janeiro, \\ $R J$, Brazil; ${ }^{b}$ Department of Mechanical and Materials Engineering, \\ Military Institute of Engineering, 22290-270, Rio de Janeiro, RJ, Brazil
}

(Received 3 February 1999)

\begin{abstract}
Diagrams of remanent induction, $\boldsymbol{B}_{\mathrm{r}}$, versus saturation induction, $\boldsymbol{B}_{\mathrm{s}}$, for $\mathbf{F e}-5 \mathrm{Ni}-x \mathrm{Mo}-$ $0.05 \mathrm{C}$ alloys, where $x$ is equal to $11 \%, 15 \%$ or $19 \%$, were determined for samples $60 \%$, $80 \%, 90 \%$ and $97 \%$ cold rolled and magnetically age-annealed at $610^{\circ} \mathrm{C}$ for $1 \mathrm{~h}$. The texture evolution in those alloys was analysed as a function of rolling reduction, by means of the orientation distribution function (ODF). The results show that a sharp $\{100\}\langle 110\rangle$ texture component develops in the $11 \%$-Mo alloy for rolling reductions in excess of $90 \%$. This leads to the highest values of the remanent induction, $\boldsymbol{B}_{\mathrm{r}}$, and of the $\boldsymbol{B}_{\mathrm{r}} / \boldsymbol{B}_{\mathrm{s}}$ ratio for this alloy as a result of $\langle 100\rangle$ directions, the easy magnetization directions, lying at $45^{\circ}$ to the rolling direction.
\end{abstract}

Keywords: Cold rolling; Magnetic aging; Texture

\section{INTRODUCTION}

$\mathrm{Fe}-\mathrm{Mo}-\mathrm{Ni}$ alloys are highly ductile materials with magnetic properties similar to those displayed by commercial $\mathrm{Fe}-50 \mathrm{Co}-(3-14) \mathrm{V}$. Their main advantage over the latter is the absence of the expensive element cobalt. These alloys have a bcc structure from room temperature to

* Corresponding author. 
$1200^{\circ} \mathrm{C}$ (Jim and Tiefel, 1981) which, together with their high ductility, makes them amenable to magnetic property improvement via thermomechanical treatments.

Magat et al. (1988) showed that severe cold deformation prior to magnetic aging improves the remanent induction $B_{\mathrm{r}}$ and coercive force $H_{\mathrm{c}}$ of $\mathrm{Fe}-20 \mathrm{Mo}-5 \mathrm{Ni}$ alloys. They showed that both the textural and magnetic anisotropies are a result of the cold deformation introduced in these alloys. Tavares et al. (1994) showed that the addition of $0.12 \%$ carbon improves $B_{\mathrm{r}}$ and $H_{\mathrm{c}}$ but the alloys become brittle, probably as a result of grain boundary carbide precipitation. Jim and Tiefel (1981), studying $\mathrm{Fe}-\mathrm{Mo}-\mathrm{Ni}$ alloys, found very low values of $H_{\mathrm{c}}$ for the compositions with low Mo content.

In a previous work in this same journal, Abreu et al. (1998) cold rolled $\mathrm{Fe}-20 \mathrm{Mo}-5 \mathrm{Ni}-x \mathrm{C}$, with $x$ varying between $0.020 \%$ and $0.092 \%$ in weight, to different reductions up to $99 \%$. They showed that in the samples cold rolled between $80 \%$ and $90 \%$ there was a decrease in the volume fraction of the $\{001\}\langle 100\rangle$ orientation while in those cold rolled $97 \%$ and $99 \%$ an increase was observed, after age-annealing. Their results also indicated that the increase in the $\{001\}\langle 100\rangle$ volume fraction depended strongly on alloy composition.

The goal of the present work is to determine the influence of the Mo content on the textural changes in $\mathrm{Fe}-\mathrm{Mo}-5 \mathrm{Ni}-0.05 \mathrm{C}$ alloys and relate these changes to the observed variation in magnetic properties. This is part of a more comprehensive investigation on $\mathrm{Fe}-\mathrm{Mo}-\mathrm{Ni}-\mathrm{C}$ alloys being carried out by the authors.

\section{EXPERIMENTAL}

Three $\mathrm{Fe}-\mathrm{Mo}-5 \mathrm{Ni}-0.05 \mathrm{C}$ ingots were prepared by induction melting under vacuum. The composition of each ingot is shown in Table $\mathrm{I}$. The ingots were soaked at $1250^{\circ} \mathrm{C}$ for $30 \mathrm{~min}$ and hot rolled to $60 \%$ reduction

TABLE I Chemical composition of the alloys in weight percent

\begin{tabular}{lccccc}
\hline Alloy & $C$ & $N i$ & $M o$ & $C o$ & $F e$ \\
\hline B & 0.052 & 5.0 & 11.0 & $<0.01$ & balance \\
H & 0.050 & 4.7 & 14.5 & $<0.01$ & balance \\
M & 0.057 & 5.0 & 19.3 & $<0.01$ & balance \\
\hline
\end{tabular}


in one pass. The strips were reheated to $1220^{\circ} \mathrm{C}$ and quenched in water. The hot-rolled strips were cold rolled to $60 \%, 80 \%, 90 \%$ and $97 \%$ whence samples were removed. Magnetic aging of these samples was carried out at $610^{\circ} \mathrm{C}$ for $1 \mathrm{~h}$.

The magnetic properties and the hysteresis loops were measured in a vibrating sample magnetometer EGG-PAR model 4500.

The samples for texture measurement were $20 \mathrm{~mm} \times 14 \mathrm{~mm}$ rectangles cut from the sheets with the smaller dimension parallel to the rolling direction. These were ground to a 600-mesh finishing and chemically polished in a solution of $\mathrm{HF}$ in $\mathrm{H}_{2} \mathrm{O}_{2}$.

The crystallographic textures were determined by calculating the orientation distribution function - ODF - using the Roe method (Roe, 1965). The ODFs were computed from experimental $\{110\},\{200\}$ and $\{211\}$ incomplete pole figures using a series of spherical harmonics expanded to $l=22$. The orientation density distributions were represented in $\varphi_{2}=45^{\circ}$ sections in Bunge coordinates (Bunge, 1993).

\section{RESULTS AND DISCUSSION}

Figure 1(a)-(c) shows the ODF $\varphi_{2}=45^{\circ}$ sections for alloys $\mathrm{B}, \mathrm{H}$ and $\mathrm{M}$ cold rolled $80 \%, 90 \%$ and $97 \%$ and magnetically aged at $610^{\circ} \mathrm{C}$ for $1 \mathrm{~h}$. It can be seen that the fibres that characterize the bcc texture become sharper for reductions above $80 \%$. The increase in sharpness with rolling reduction is better observed in Fig. 1(a), for alloy B (11\% Mo); the sharpness decreases with increasing Mo content. The texture development is similar to that observed in rimming steels, but it is retarded with respect to the latter when the textures for the same rolling reduction are compared. The texture seems to be the result of a normal cold rolling and recrystallization behaviour when the latter is hindered by the presence of fine precipitates (not confirmed in this work). The main components are $\{001\}\langle 1 \overline{1} 0\rangle,\{111\}\langle 0 \overline{1} 1\rangle$ and $\{111\}\langle 1 \overline{2} 1\rangle$.

Figure 2 shows the variation of the $\{001\}\langle 110\rangle$ ODF intensity with cold rolling reduction for the three alloys. One can observe that the maximum intensity, 22 times random, is attained by alloy $\mathbf{B}$, containing $11 \% \mathrm{Mo}$, and for the $97 \%$ cold reduction condition. The curve for alloy $B$ also shows that the development of this orientation is accelerated for reductions above about $90 \%$. This is an important result since it leads 

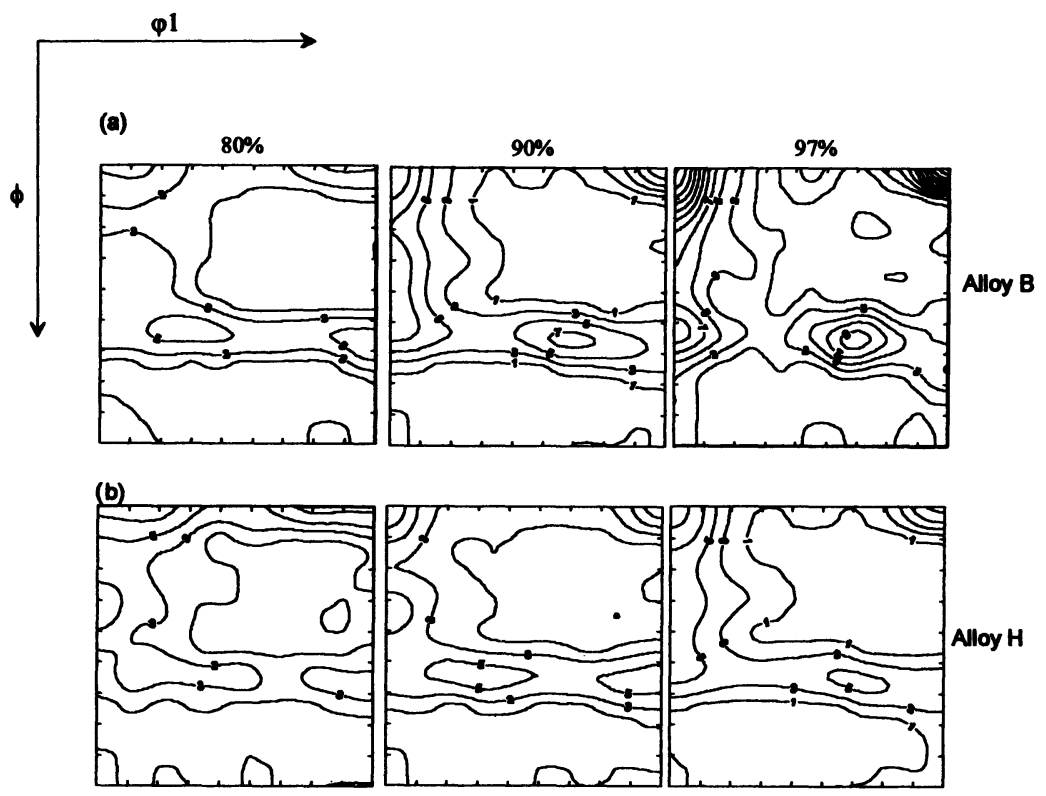

(c)

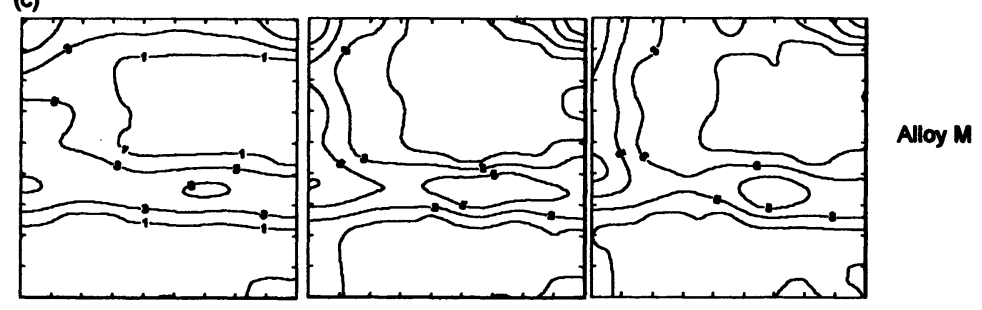

FIGURE 1 ODF $\varphi_{2}=45^{\circ}$ sections for alloys $B, H$ and $M$ (contours at $1,3,5, \ldots$ ).

to an increase in the magnetic anisotropy on account of the $\langle 100\rangle$ directions, the direction of easy magnetization, lying in the sheet plane at $45^{\circ}$ to the rolling direction.

Figure 3 shows the variation of the texture severity parameter - TSP with cold rolling reduction for the three alloys. The TSP measures the depart of the texture from random and is equal to unity for the uniform distribution. It can be seen that the increase in TSP is larger for alloy B, in agreement with the trend observed in Fig. 1. The curves in Figs. 2 and 3 are similar in shape. The increase in TSP results mainly from the increase in the $\{001\}\langle 110\rangle$ volume fraction. From the data in both Figs. 2 and 3 




FIGURE 2 Variation of the ODF intensity of the $\{001\}\langle 110\rangle$ orientation with cold rolling reduction.

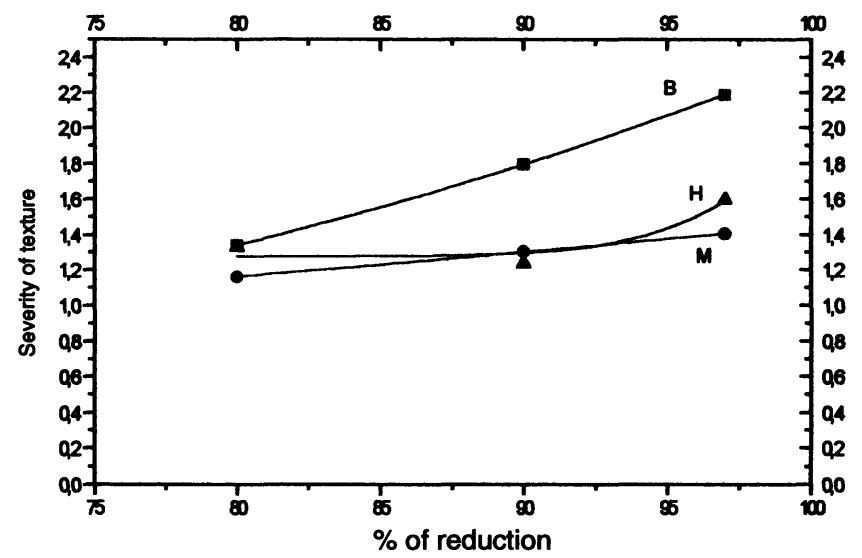

FIGURE 3 Variation of the texture severity parameter, TSP, with cold rolling reduction.

one can see that the development of the $\{001\}\langle 110\rangle$ component with rolling reduction is hindered by the increase in Mo content.

Figure 4 shows the variation of the ratio between remanent induction and saturation induction, $B_{\mathrm{r}} / \boldsymbol{B}_{\mathrm{s}}$ with cold reduction. It is generally accepted that this ratio, when larger than 0.8 , is an indication of magnetic anisotropy. It can be seen that all three alloys show magnetic anisotropy for reductions equal to and higher than about $80 \%$. In fact, both 


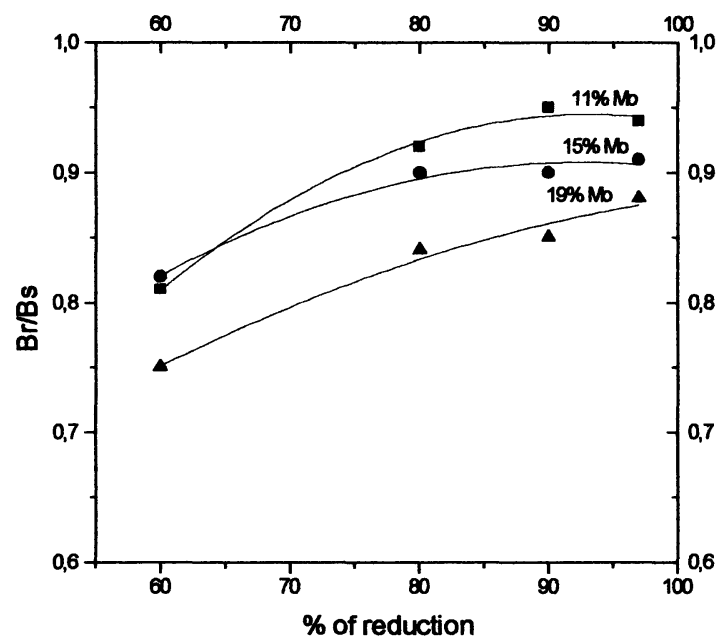

FIGURE 4 Variation of the $B_{\mathrm{r}} / \boldsymbol{B}_{\mathrm{s}}$ ratio with rolling reduction for alloys $\mathrm{B}, \mathrm{H}$ and $\mathrm{M}$.

alloys $\mathrm{B}$ and $\mathrm{H}$ satisfy that condition for the whole range above $60 \%$ reduction. For $97 \%$ cold reduction the $B_{\mathrm{r}} / B_{\mathrm{s}}$ ratio is $0.94,0.88$ and 0.81 , respectively, for alloys $\mathrm{B}, \mathrm{H}$ and $\mathrm{M}$. The deleterious effect of the Mo content can again be observed. The coercive force, $H_{\mathrm{c}}$, practically did not vary with rolling reduction for any of the three alloys. The average values were about 280,320 and $350 \mathrm{Oe}$, for alloys $\mathrm{B}, \mathrm{H}$ and $\mathrm{M}$, respectively.

Figure 5 shows the second quadrant of the hysteresis loop for alloys $B$ (11\% Mo) H (15\% Mo) and M (19\% Mo). Figure 5(a), for alloy B, shows an almost perfect square relation between $B_{\mathrm{r}}$ and $B_{\mathrm{s}}$ leading to high $B_{\mathrm{r}} / B_{\mathrm{s}}$ ratios. Both these figures reflect again the influence of the Mo content and the corresponding increase in the $\{001\}\langle 110\rangle$ volume fraction.

\section{CONCLUSIONS}

Three $\mathrm{Fe}-5 \mathrm{Ni}-x \mathrm{Mo}-0.05 \mathrm{C}$ alloys, where $x$ is $11 \%, 15 \%$ or $19 \%$, were cold rolled $60 \%, 80 \%, 90 \%$ and $97 \%$ and magnetically aged at $610^{\circ} \mathrm{C}$ for $1 \mathrm{~h}$. The texture in these alloys shows the typical carbon steel-like development of the $\{h k l\}\langle 110\rangle$ and $\{111\}\langle u v w\rangle$ partial fibres, these reaching the highest values for the $11 \%$ Mo alloy and decreasing with 

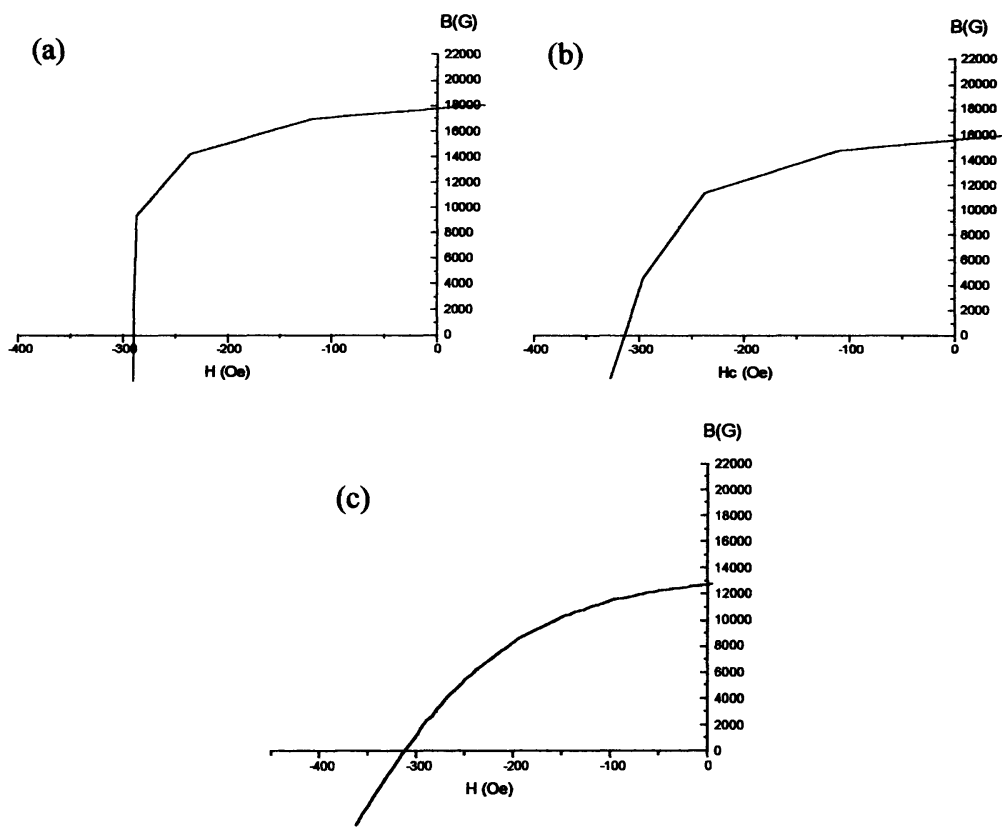

FIGURE 5 Second quadrant of the hysteresis loops for the $97 \%$ cold rolled and magnetically aged samples of the alloys with (a) $11 \% \mathrm{Mo}$, (b) $15 \% \mathrm{Mo}$, (c) $19 \% \mathrm{Mo}$.

increasing Mo content. The ODF intensity of the $\{001\}\langle 110\rangle$ component continuously increase with rolling reduction, for the $11 \%$ Mo alloy only, and reaches a maximum at $97 \%$ reduction. This increase is responsible for the high $B_{\mathrm{r}} / B_{\mathrm{s}}$ ratios observed in this alloy. Taking into account the results obtained by Abreu et al. (1998) on the influence of the carbon content in $\mathrm{Fe}-\mathrm{Mo}-\mathrm{Ni}-\mathrm{C}$ alloys, the alloy $\mathrm{Fe}-11 \mathrm{Mo}-5 \mathrm{Ni}-0.05 \mathrm{C}$ seems to be an optimized composition, displaying high magnetic properties and cold ductility and having the advantage of being less costly than Co-containing alloys.

\section{References}

Abreu, H.F.G., Teodosio, J.R. and Da Costa Viana, C.S. (1998) Texture in cold rolled and magnetically aged $\mathrm{Fe}-\mathrm{Mo}-\mathrm{Ni}-\mathrm{C}$ Alloys, Texture and Microstructures (in press).

Bunge, H.J. (1982) Texture Analysis in Material Science, Mathematical Methods, Butterworths publ. London. 2nd Edn, Curvillier Verlag, Gottingen, 1993.

Jim, S. and Tiefel, T.H. (1981) New ductile Fe-Mo-Ni magnet alloys, Journal of Applied Physics, 52(3), 2503-2506. 
Magat, E.M., Makarov, G.M., Lapina, L.P. and Beloterov, E. (1988) Fis. Metal. Metaloved, 55, 1075.

Roe, R.J. (1965) Journal of Applied Physics, 36, 2024.

Tavares, S.M., Moura, M.P. and Teodósio, J.R. (1994) Magnetic properties of an Fe-20Mo-5Ni-0.12C Alloy. Journal of Magnetism and Magnetic Materials, 137, $103-106$.

Tavares, S.M., Pires, M.M. and Teodósio, J.R. (1995) Microstructural features of an Fe-20Mo-5Ni-0.12C magnetic alloy. Scripta Metallurgica et Materialia, 33, 251-257. 